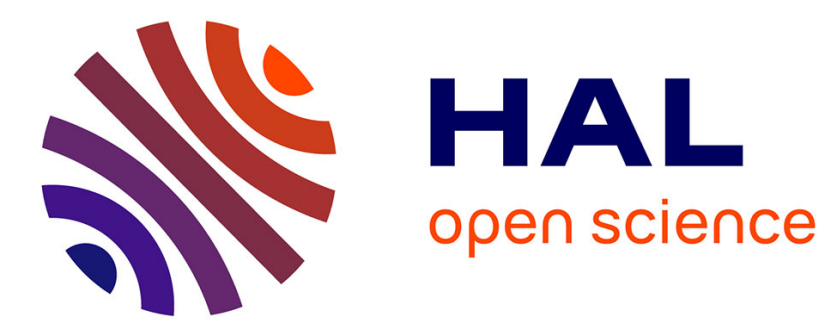

\title{
Shear Fatigue Behaviour of Tack Coats in Pavements
}

Malick Diakhaté, Annabelle Phelipot-Mardelé, Anne Millien, Christophe Petit

\section{To cite this version:}

Malick Diakhaté, Annabelle Phelipot-Mardelé, Anne Millien, Christophe Petit. Shear Fatigue Behaviour of Tack Coats in Pavements. Road Materials and Pavement Design, 2006, 7 (2), pp.201-222. 10.3166/rmpd.7.201-222 . hal-00521910

\section{HAL Id: hal-00521910 https://hal.science/hal-00521910}

Submitted on 29 Sep 2010

HAL is a multi-disciplinary open access archive for the deposit and dissemination of scientific research documents, whether they are published or not. The documents may come from teaching and research institutions in France or abroad, or from public or private research centers.
L'archive ouverte pluridisciplinaire HAL, est destinée au dépôt et à la diffusion de documents scientifiques de niveau recherche, publiés ou non, émanant des établissements d'enseignement et de recherche français ou étrangers, des laboratoires publics ou privés. 


\title{
Shear Fatigue Behaviour of Tack Coats in Pavements
}

\author{
Malick Diakhate - Annabelle Phelipot - Anne Millien \\ Christophe Petit
}

\author{
Laboratoire $3 M s G C$ \\ Centre universitaire de génie civil \\ Bd Jacques Derche \\ F-19300 Egletons \\ malick.diakhate@etu.unilim.fr \\ phelipot@unilim.fr \\ millien@egletons.unilim.fr \\ christophe.petit@unilim.fr
}

\begin{abstract}
For many years, pavement engineers use mechanistic design methods that are based on algorithms to compute stresses, strains and displacements in a flexible pavement structure, or in a multi-layered structure in general. Most of these methods assume, to ease the modelling of the structure and the computation process, that the layers are fully bonded or completely unbounded to each other. Moreover, determining the effectiveness of the bonding between two layers is difficult since there is no standard test procedure to assess it. Hence, proper modelling of the interface bonding condition will represent an important finding in understanding the real behaviour of road structures, and will lead to reduce maintenance and rehabilitation costs. Asphalt emulsion is commonly used, as tack coat, to ensure the bond between two pavement layers. This study deals with an experimental characterization of interfaces shear fatigue behaviour through laboratory tests. A testing device for determining the shear fatigue behaviour is described in this paper. Shear fatigue tests, at a temperature of $5^{\circ} \mathrm{C}$ and a frequency of $1 \mathrm{~Hz}$, were performed on asphalt concrete mix layers interface with tack coat. Samples were subjected to a cyclic symmetrical alternate shearing load at the interfaces, aiming interfaces failures within the range of $10^{4}$ to $10^{5}$ cycles of loading. Within this range of number of cycles, the fatigue results indicate a linear evolution of the initial shear stress half-amplitude with the decimal logarithm of the number of cycles to failure. These results are used to derive a linear fatigue law, which will serve to model the real behaviour of the interface with tack coat studied in this research.
\end{abstract}

KEYWORDS: Tack Coat, Interface, Pavement, Fatigue, Shear, Behaviour.

Road Materials and Pavement Design. Volume 7 - No. 2/2006, pages 201 to 222 


\section{Introduction}

Pavement design method is based on criteria of fatigue behaviour of bituminous materials and, on criteria of rutting of unbound layers. The behaviour of in-service pavements shows the importance of ensuring a good bond at the interface between layers. Slippage and complete separation of layers can occur if the layers are inadequately bonded. Reflective cracking, delamination and potholes may appear if the layers are separated. The functionality of the pavement structure is then compromised. All these distresses listed could be reduced or eliminated, if the interface bonding condition is taken fully into account in the structural design of pavement (Romanoschi and Metcalf, 2001).

Spraying an asphalt emulsion over an underlayer before laying an asphalt surface course is a technique commonly used for providing the bonding between pavement layers to make sure they act as monolithic system to withstand traffic and environmental loads. Tack coat important parameters usually considered are its application rate, its thickness, the material constituting the tack coat and the surface roughness of the layers to be sprayed.

Under traffic load, pavement structure is subjected to a fatigue load. Loads acting at the interfaces between layers are also cyclic. Fatigue is, in general and mainly, the cause of the cracks appearance on pavement surface. Field-observations showed the need of ensuring an excellent bond of the adjacent layers of pavement structures, particularly in areas where the vehicles are more likely to apply horizontal forces, such as, small-radius curves, steep ramps and areas of braking-acceleration. In these areas, critical shear stresses are often encountered, especially at the interface between the wearing and base layers or at the interface between the wearing and binder layers (Romanoschi, 1999).

Even though the field-observations on roads indicate the need to understand interfaces real behaviour to better compute the useful life of a pavement structure, very few studies have focused on developing testing methodologies and formulating constitutive models for interfaces. Some researchers (Uzan et al., 1978; Millien, 1996; Romanoschi, 1999; Romanoschi and Metcalf, 2001; Mohammad et al., 2002; (Collop et al., 2003) have investigated interfaces behaviour through direct shear tests, fatigue tests, and numerical modelling. Some of these tests and their major findings will be presented more in detail in this paper. A previous shear fatigue test was performed on asphalt concrete mix specimens (Petit et al., 2002), where a shear band, modelling a crack, is subjected to a fatigue load. This method is used to test interfaces in shear fatigue and is presented in this paper.

The objective of this study is to better understand the shear fatigue behaviour of tack coats and to develop tests or methods that allow showing the relevance of tack coats and its fatigue behaviour. 


\section{Problem description}

French design method (LCPC, 1994) considers full bonding interface condition between asphalt concrete mix layers and a complete slip between an asphalt mix layer and a layer treated with hydraulic binder. These two assumptions do not really represent the real behaviour of the interface, and then, can lead to an inappropriate design of the pavement structure. However, tack coat behaviour is not taken into account, and incorporating its behaviour into the pavement design method will represent a technological advance in understanding the real behaviour of tack coats as well as a more economic design.

Under traffic load (Figure 1), the interface is subjected to shear and normal stresses. By use of the finite element program computer CAST3M, a flexible pavement structure (Table 1) is calculated. The wearing and the base layers, both in asphalt concrete mix, are fully bonded. The pavement structure is subjected to a wheel of the French standard axle (LCPC, 1994). This wheel exerts a vertical pressure of $0.662 \mathrm{MPa}$ uniformly distributed on a disc of $125 \mathrm{~mm}$ radius. Mechanical and geometrical characteristics of the studied pavement structure, chosen from the French pavements design catalogue (LCPC, 1998), are summarized in Table 1. Figure 2 and Figure 3 show computed stresses diagrams at the interface between the wearing and the base layers.

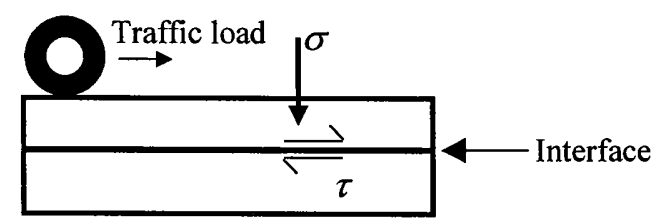

Figure 1. Stress field at the interface

Table 1. Geometrical and mechanical characteristics of pavement layers

\begin{tabular}{|l|l|c|c|c|}
\hline \multicolumn{1}{|c|}{ Layer } & \multicolumn{1}{|c|}{ Material } & $\begin{array}{c}\text { Thickness } \\
{[\mathrm{mm}]}\end{array}$ & $\begin{array}{c}\text { Young's modulus } \\
{[\mathrm{MPa}]}\end{array}$ & $\begin{array}{c}\text { Poisson's } \\
\text { ratio }\end{array}$ \\
\hline Wearing & Asphalt concrete mix & 60 & 5400 & 0.35 \\
\hline Base & Asphalt concrete mix & 100 & 9300 & 0.35 \\
\hline Foundation & Crushed stones & 350 & 125 & 0.35 \\
\hline Subgrade & Soil & - & 50 & 0.35 \\
\hline
\end{tabular}




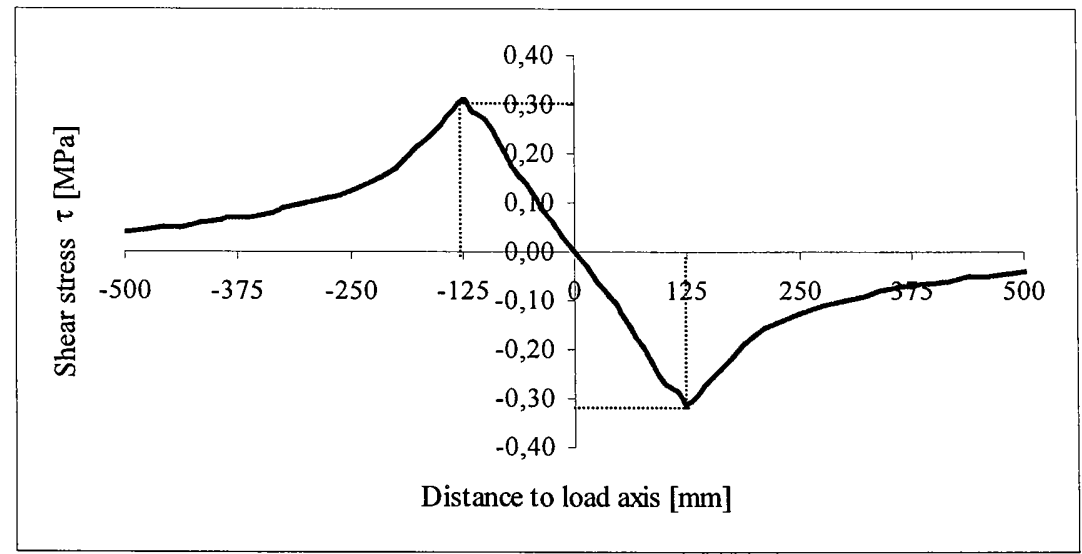

Figure 2. Computed shear stress diagram at the wearing-base layers interface (fully bonded) under a French standard wheel load

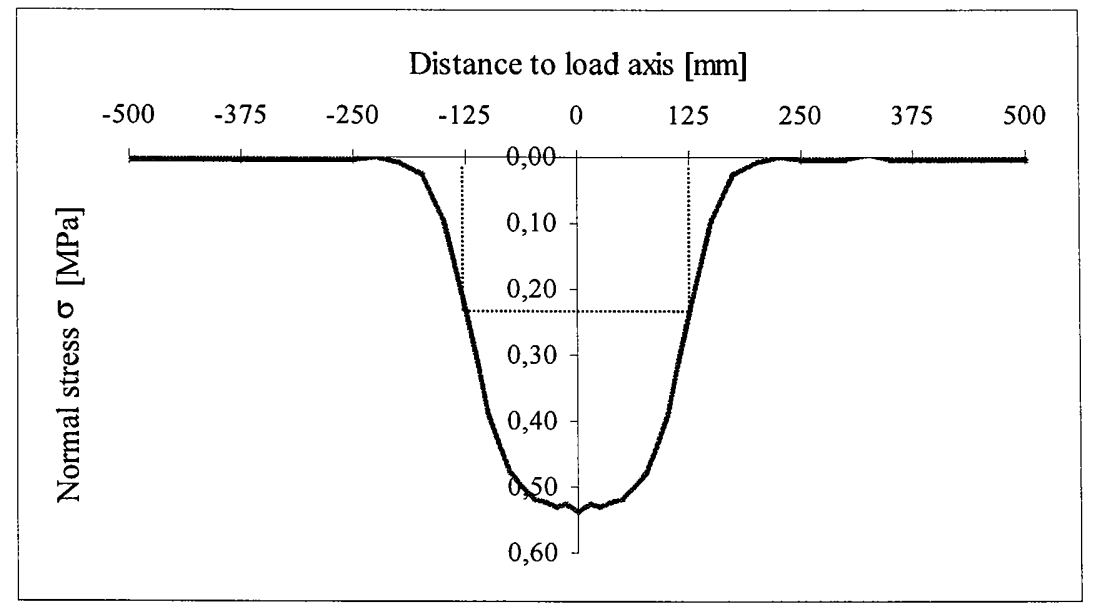

Figure 3. Computed normal stress diagram at the wearing-base layers interface (fully bonded) under a French standard wheel load

According to Figure 2, it is remarked that, under a wheel load, the interface is subjected to a symmetrical alternate shearing load. The maximum shear stress value is located at the edges of the load $(\mathrm{x}= \pm 125 \mathrm{~mm})$ with $\tau= \pm 0.30 \mathrm{MPa}$ and the corresponding normal stress $\sigma=0.23 \mathrm{MPa}$ (Figure 3); so the magnitude of the shear stress $\tau$ is almost of the same order as $\sigma$ in flexible pavements. 
Under traffic load, the interface is then subjected to a repetitive symmetrical alternate shearing load (shear fatigue). When one is interesting to particular road sections as braking-acceleration areas, the ratio $\tau / \sigma$ becomes much higher. Thus, it is possible, in these cases, to assume that only horizontal loads are applied at the interface.

\section{Background}

As mentioned in the paragraph 1, even though the field-observations on road structures indicate the need to understand interfaces real behaviour, very few studies have focused on developing testing methodologies and formulating constitutive models for interfaces between pavement layers. Most of these research studies are still in development.

\subsection{Interface direct shear test with normal load}

Most of the research studies on interface behaviour deal with tack coat direct shear tests. Uzan et al. (1978) conducted an extensive laboratory investigation of the mechanical properties of asphalt concrete layer interfaces. Asphalt samples were tested at two temperatures $\left(25^{\circ} \mathrm{C}\right.$ and $\left.55^{\circ} \mathrm{C}\right)$, five levels of normal pressure $(0,50$, $100,250$ and $500 \mathrm{kPa})$, and one rate of shear $(2.5 \mathrm{~mm} / \mathrm{min})$. Five application rates of tack coat $\left(0,0.5,1,1.5\right.$ and $\left.2 \mathrm{~kg} / \mathrm{m}^{2}\right)$ were applied to determine the influence on the mechanical properties of the interface and to approximately estimate the tack coat application rate that led to the highest interface shear strength. The major findings from these interface shear tests were as follows (Romanoschi and Metcalf, 2001):

- The shear stress against the relative shear displacement is linear until the shear strength of the interface $\tau_{\max } ; \mathrm{K}$ (interface shear stiffness) is the slope. Interface failure occurs when the shear stress reaches the shear strength of the interface.

- The shear strength and the shear stiffness of the interface increase with the normal pressure and decrease with the temperature. The influence of temperature is reduced when the normal pressure increase;

- For the material combinations tested, the optimum amount of tack coat was 1 $\mathrm{kg} / \mathrm{m}^{2}$, and the tack coat rate had a small influence on the mechanical properties of the fresh asphalt mix concrete interface; the influence could be different on an aged asphalt concrete.

This last finding is probably due to the high temperatures $\left(25\right.$ and $\left.55^{\circ} \mathrm{C}\right)$ chosen in Uzan et al. (1978) study. In fact, Millien et al. (1996) had conducted direct shear tests without normal load on interfaces with tack coat; a part of this study was to investigate the influence of tack coat application rate on interface shear strength. Tests were performed at three temperature levels $\left(0,25\right.$ and $\left.40^{\circ} \mathrm{C}\right)$, four application rates of tack coat $\left(200,300,400\right.$ and $\left.500 \mathrm{~g} / \mathrm{m}^{2}\right)$ and shear displacement velocity 
$(1 \mathrm{~mm} / \mathrm{s})$. Optimum tack coat rate was $300 \mathrm{~g} / \mathrm{m}^{2}$. Results clearly show that the influence of tack coat application rate on interface shear strength is more and more outstanding when the test temperature decreases. Millien et al. results also show that temperature greatly influences the interface shear strength as well as interface shear stiffness, interface shear strength decreases in a non-linear way when the temperature level increases (Millien et al., 1996).

Romanoschi et al. (Romanoschi, 1999; Romanoschi and Metcalf, 2001) had also conducted interface direct shear tests with normal load. In their study, interfaces with $\left(0.1 \mathrm{l} / \mathrm{m}^{2}\right)$ and without tack coat had been investigated. Direct shear tests at several normal pressures were performed on asphalt-to-asphalt interfaces. The samples, with $95 \mathrm{~mm}$ diameter, were extracted from the Louisiana Pavement Research Facility site. Test parameters were a displacement rate of $0.2 \mathrm{~mm} / \mathrm{s}$, three temperature levels $\left(15,25\right.$ and $\left.35^{\circ} \mathrm{C}\right)$ and four normal pressure levels $(138,276,414$ and $522 \mathrm{kPa}$ ). The major findings of this research study were the same as those mentioned above (Uzan et al. results); but another finding on interface behaviour with respect to the type of interface (with or without tack coat) is:

- For the interface with tack coat, the shear strength and shear stiffness values seem to be not affected by the normal stress levels applied, but they are affected for the interface without tack coat. Romanoschi et al. explained this finding by the presence of voids at the interface without tack coat. In fact, with respect to four normal pressure levels listed above, the increase in normal stress causes an increase in the area of the contact surface, therefore, higher shear stiffness and higher shear strength. When the tack coat is present, the voids are filled with tack coat and the increase in normal stress does not lead to an increase in the contact surface. Therefore, the shear stiffness and the shear strength of the interface do not increase (Romanoschi and Metcalf, 2001).

- In relation to normal stress influence on interface shear strength as well as interface shear stiffness, findings from Uzan et al. study and those from Romanoschi et al. study seem to be different even if normal stress levels applied are quite of the same order. By studying interface with tack coat behaviour, on the one hand, Uzan founded that interface mechanical properties (shear strength and shear stiffness) increase with the normal pressure, and on the other hand, Romanoschi founded that the normal stress level does not affect these interface mechanical properties. Direct comparison between these specific findings is not easy since tack coat application rates are not in the same units (one in $\mathrm{kg} / \mathrm{m}^{2}$ and the other in $1 / \mathrm{m}^{2}$ ).

\subsection{Interface shear fatigue test}

As observed earlier in the paragraph 2, under traffic load, the pavement structure is subjected to a repetitive mechanical action of the moving vehicles. Hence, the loads acting at the interfaces between layers are also cyclic, and therefore it is important to investigate the fatigue behaviour of the interfaces. It should be noted 
that accurate laboratory simulation of the stress field at the interface is very difficult. At a given point of the interface, the ratio of shear to normal stresses varies as the vehicle approaches and recedes from that point (Romanoschi and Metcalf, 2001).

In this study, Romanoschi et al. proposed the test configuration, presented in Figure 4 , to conduct shear fatigue tests on asphalt concrete layer interfaces. The longitudinal axis of the specimen is at $25.5^{\circ}$ with the vertical so that the shear stress at the interface is half the normal stress. Computations in figure 2 and figure 3 shows that this hypothesis is restrictive because we also have great shear stresses without normale stresses. In a time quite the same, the shear and normal stresses are in the same order. In reality the ratio $\tau / \sigma$ always changes so the test in figure 4 can represent the sollicitation around shear peak (cf. Figures 2 and 3).

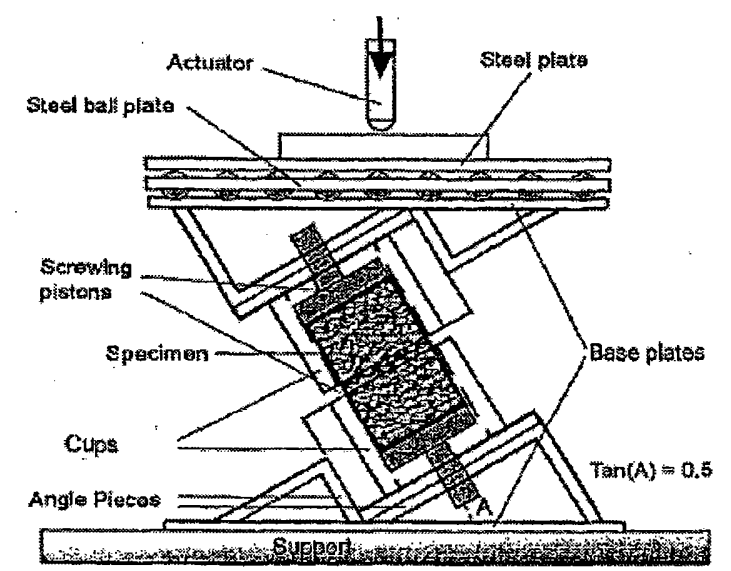

Figure 4. Schematic of shear fatigue test (Romanoschi, 1999; Romanoschi and Metcalf, 2001)

A vertical load was applied with a minimum load of $10 \%$ of the maximum load, with a frequency of $5 \mathrm{~Hz}$. So, the total period was $0.2 \mathrm{~s}$ and the length of the pulse was $0.05 \mathrm{~s}$, simulating the pass of a vehicle at $50 \mathrm{~km} / \mathrm{h}$. Fatigue tests on two types of interfaces (with and without tack coat) were performed at $25^{\circ} \mathrm{C}$, and by applying four vertical load levels of $4,6,8$ and $10 \mathrm{kN}$. The corresponding normal stresses at the interface, $0.5,0.75,1.0$ and $1.25 \mathrm{MPa}$, are within the range of normal stress values for interfaces of road and airfield pavements (Romanoschi, 1999; Romanoschi and Metcalf, 2001).

The elastic and permanent displacements at the interface in normal and tangential directions were recorded for each cycle. The fatigue tests were stopped when the Permanent Shear Displacement (PSD) at the interface reached $6 \mathrm{~mm}$ or 
when it was considered that the number of cycles corresponding to a PSD of $6 \mathrm{~mm}$ could be extrapolated. Through these shear fatigue tests, Romanoschi et al. remarked that the PSD increases at a constant rate with the number of load cycles; the shear stress is uniformly distributed over the interface area. PSD increases up to the point when the interface fails, after which, friction between the layers in contact at the interface will continue to resist the relative movement of the two layers.

In order to characterize the evolution of PSD with the number of load repetitions, Romanoschi et al. had computed the parameter ND1, which represents the number of load cycles that leads to an increase of PSD of $1 \mathrm{~mm}$. ND1 can be used as a parameter for comparative evaluation of the fatigue properties of the asphalt-toasphalt interfaces; the higher the ND1 value, the more durable is the interface. The major findings from this analysis are as follows (Romanoschi, 1999 ; Romanoschi and Metcalf, 2001):

- ND1 varies greatly even for the same normal stress level;

- The highest variation was evident for the interface with tack coat, possibly because of variations in the thickness of the tack coat film that generates variation in the contact surface between the aggregate grains;

- The smallest variation was obtained for the interface without tack coat at the lowest normal stress level. Only for the highest normal stress was ND1 greater for the interface without tack coat. This clearly indicates that interface with tack coat has a longer life than the interface without tack coat.

\subsection{Conclusion}

Summarizing the background presented in this paper, the few existing research studies on interfaces behaviour led to the following major findings:

- Under a direct shear test with or without a normal load, the shear stress and the relative displacement are quite proportional until the shear strength of the interface, after which the interface fails. After failure, a friction model may be used to represent the interface condition. Three parameters were considered to completely describe the interface behaviour: the shear stiffness $\mathrm{K}$, the shear strength $\tau_{\text {max }}$ and the friction coefficient after failure $\mu$. All these three parameters are temperature dependent;

- According to Romanoschi, for the interface with tack coat, the parameters $\mathrm{K}$ and $\tau_{\text {max }}$ seem to be not affected by the normal stress level, but they are affected for the interface without tack coat. Concerning this finding, Uzan et al. found contradictory result;

- The asphalt layer interface may also fail in fatigue, the increase of the PSD with the number of load repetitions being linear. As expected, the rate of increase is higher for higher stresses. The fatigue test can be used for a comparative evaluation of the durability of different types of interfaces. 


\section{Experimental design}

It should be noted that there is not yet normalized shear test procedure in France to assess the effectiveness of bond between pavement layers under well controlled conditions (loading rate, temperature, etc). The laboratory "Mechanic and Modelling of Materials and Structures in Civil Engineering" (3MsCE) of the University of Limoges (France) performs a Modified Compact Shearing (MCS) test on parallelepipedic specimens to investigate asphalt concrete mix behaviour in shear fatigue (Laveissiere, 2002; Petit et al., 2002). This shear test procedure is chosen to derive tack coats shear behaviour (Millien et al., 1996). Figure 5 shows the principle of the MCS test adopted by $3 \mathrm{MsCE}$. The sample is composed of three parts two by two separated, by notches when one would like to investigate shear behaviour of materials (asphalt concrete mix, wood, etc), or by interfaces as in this study to assess bond between layers. The side parts of the sample are fixed, preventing any movement, and its central part subjected to a load. The advantage of using the MCS test to investigate tack coat shear behaviour lies in the fact that both interfaces are symmetrically subjected to a pure shearing load, in comparison to some shear tests performed on specimen, comprising two layers, during which, under the applied load, the interface can be sometimes subjected to a bending moment more besides the shearing load. The experimental program is a series of cyclic shear tests, aiming interfaces failures within the range of $10^{4}$ to $10^{5}$ cycles of loading.

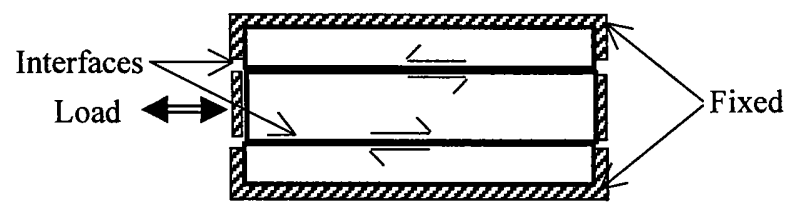

Figure 5. Schematic of the MCS test (3MsCE)

The asphalt concrete mix properties depend on the load time (or load frequency) and the test temperature at which they are measured. Through the literature, bituminous materials are usually considered to be viscoelastic and linear. In France, the bituminous materials modulus, used in pavement structures design, derived from cyclic bending tests usually carried out at the temperature of $15^{\circ} \mathrm{C}$ and at the frequency of $10 \mathrm{~Hz}$ (LCPC, 1994). According to "an equivalence" in temperature and frequency, fatigue tests are performed at $1 \mathrm{~Hz}$ and at $5^{\circ} \mathrm{C}$. Bituminous materials modulus measured at $1 \mathrm{~Hz}$ and $5^{\circ} \mathrm{C}$ are of the same order as those obtained through test carried out at $10 \mathrm{~Hz}$ and $15^{\circ} \mathrm{C}$. 


\section{Materials and specimens}

\subsection{Materials}

This study deals with the behaviour of the emulsion developed by the Centre de recherche et développement Eurovia (CRD Eurovia, France). This emulsion is used to ensure the bond between asphalt mix layers subjected to high shearing loads. Application rate adopted is $300 \mathrm{~g} / \mathrm{m}^{2}$ residual bitumen $(50-70$ pen). The asphalt concrete mix, also developed by CRD Eurovia, is an asphalt concrete mix with $0 / 10$ $\mathrm{mm}$ aggregates size, and bitumen (35-50 pen) content (percent weight) of 5.4. This asphalt concrete mix is usually used as a wearing or a binder course material (according to French design specifications).

\subsection{Specimens}

A slab of plan dimensions $500 \mathrm{~mm}$ by $180 \mathrm{~mm}$ is composed of three layers of the same asphalt concrete mix, respective thickness of 30,40 and $30 \mathrm{~mm}$. The emulsion ensures the bond between these layers. Each layer is compacted by means of a roller compactor with dual wheels. The aimed compactness is $93 \%$, which simulates a representative field compaction condition. A measured quantity of asphalt concrete mix for the lower layer, once mixed, is placed in the mould and compacted to 40 $\mathrm{mm}$ in thickness. This lower layer is then let to cool and the emulsion is uniformly sprayed on. Once the interface prepared, a rest time is recommended for the emulsion break process prior to manufacturing the upper layer by placing and compacting a new quantity of asphalt concrete mix on top of the lower layer to 30 $\mathrm{mm}$ in thickness. The processes of interface preparation and layer manufacturing, described above, are then repeated to obtain a slab comprising three layers. From the slab, twenty-six specimens $\left(70 \times 100 \times 30 \mathrm{~mm}^{3}\right)$ are extracted by means of an electric saw.

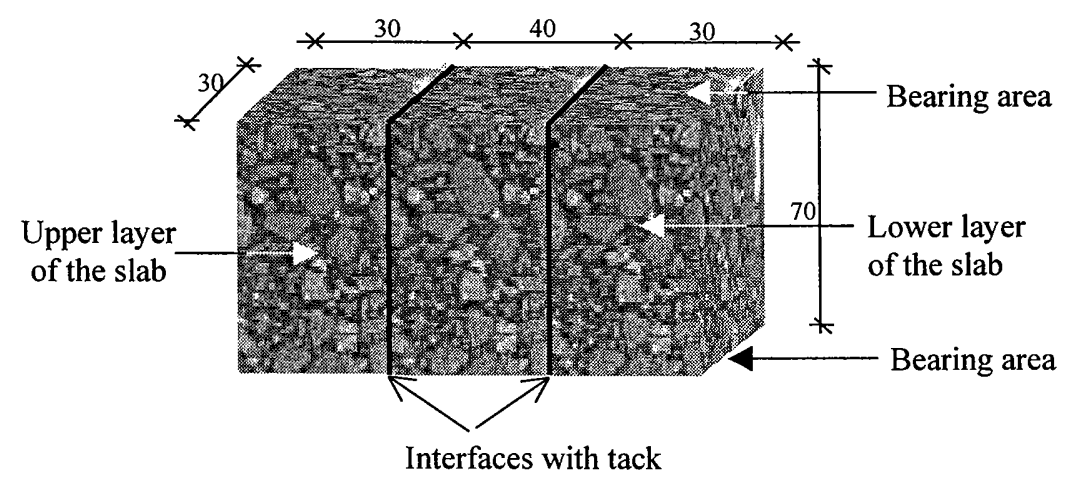

Figure 6. Three-layers specimen (dimensions in $\mathrm{mm}$ ) 


\section{Experimental procedure}

\subsection{Experimental device}

A specific shearing apparatus was modified and fabricated to hold the specimen during testing. Regarding the principle of the MCS test described earlier, the apparatus is designed so that the side layers of the specimen are fully fixed and, its central layer, interdependent of a mobile clamp, is subjected to a repetitive displacement, which generates an alternate cyclic shearing load at the interfaces. Figure 7 shows a schematic experimental device used to perform the shear fatigue tests on tack coats. At present, the configuration of this experimental device does not allow applying normal load onto the specimen.

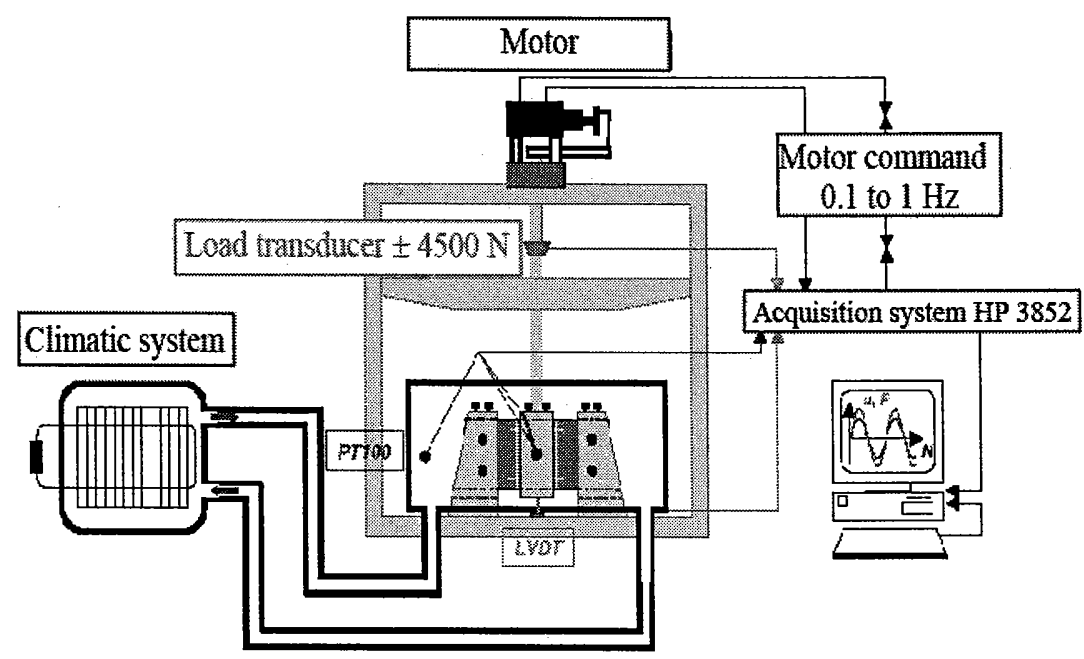

Figure 7. Schematic experimental device used to perform shear fatigue tests

An electric motor transmits, by means of a drive shaft, a symmetrical and sinusoidal alternate displacement to the central layer of the specimen, thus producing failures at interfaces. A load sensor is located on this drive shaft, with a range of measurement of $\pm 4500 \mathrm{~N}$ and a precision of $\pm 0,1 \%$. The shear displacement at the interfaces is measured by a Linear Variable Differential Transformer (LVDT) type sensor located under the steel rigid frame clamp of the central layer of the specimen. 


\subsection{Specimen preparation and installation}

Before testing, a preparation of the specimen is needed. Due to the dimensions of the specimen $\left(70 \times 100 \times 30 \mathrm{~mm}^{3}\right)$, an embedding, by sticking the specimen to the metallic holder, was chosen. An Araldite glue bi-components (resin GY257, hardener HY2958) was used to achieve this sticking process. In order to detect interfaces failures, one of the faces of the specimen was instrumented by placing four resistors according to a technique developed by Laveissiere (2002). The resistor is a very thin silver paint, handmade, and does not provide local reinforcement. Each resistor crosses an interface (Figure 8); its initial value is about of a few ohms, which tends towards infinite when the resistor is broken, in other words, when the interface has failed.

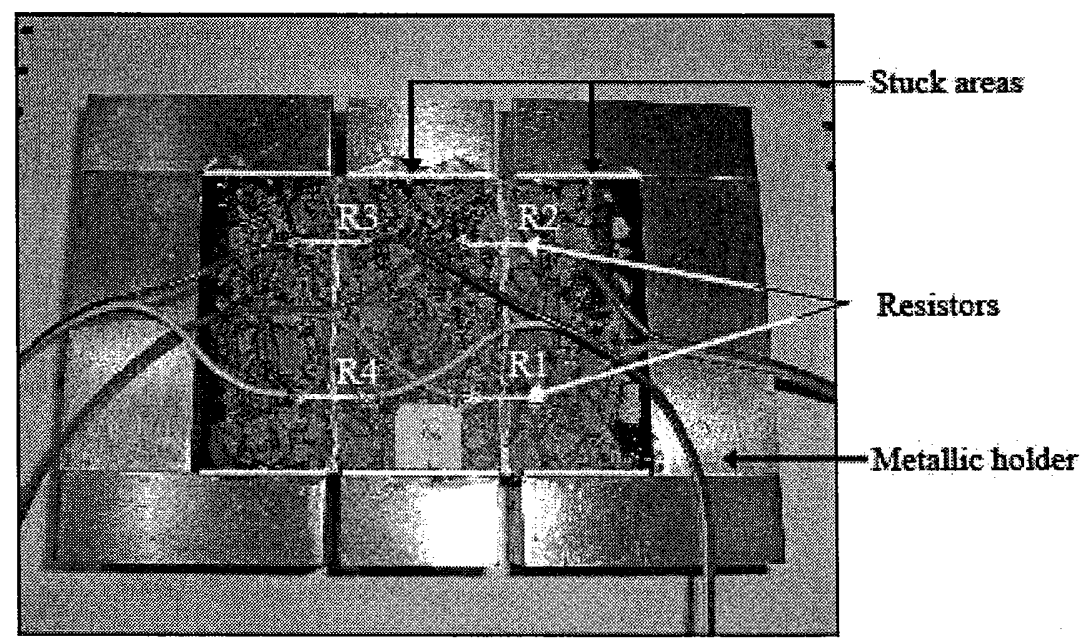

Figure 8. Instrumented specimen before testing

Throughout specimen installation, it is necessary to avoid imposing superfluous forces, torque for instance, onto the specimen. Screws, distributing tightening force on plate supports, ensure the embedding of the specimen side parts. The specimen central part, stuck to the steel rigid mobile frame clamp, is then connected to the fatigue machine drive shaft by avoiding imposing torque onto the specimen. The four resistors are then connected to an acquisition system. Once these operations done, an isothermal box is installed around the experimental device and the specimen is cooled at $5^{\circ} \mathrm{C}$ for six hours by means of a temperature controlled system. Figure 9 shows a specimen placed in the experimental device and ready to be tested in shear fatigue. 
Temperatures in the isothermal box, forces, displacements and resistors evolutions are measured and recorded by means of a data acquisition system HP $3852 \mathrm{~A}$ and the software HP VEE.

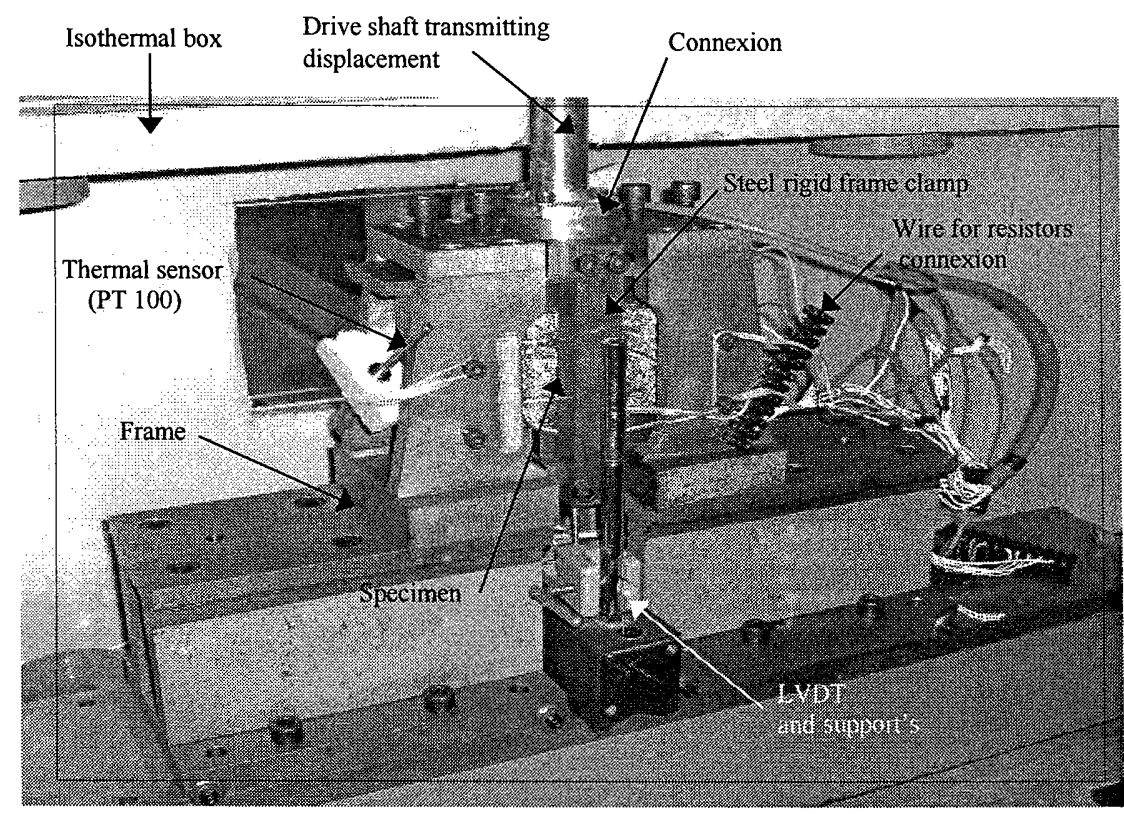

Figure 9. Specimen ready to be tested in shear fatigue

\section{Discussion of results}

\subsection{Resistors results interpretation}

As the interfaces failures approach, we can observe a progressive increase of the measured value of the resistor. When the interface has failed, the resistor value tends towards infinite.

Figure 10 shows the resistors values plotted against the number of load cycles for the fatigue shear test on the specimen (29G). From this Figure 10, it can be noticed that the resistors R1 and R4 were broken almost at the same time, towards $9.5 .10^{4}$ cycles of loading, just as R2 and R3 were broken towards $11.10^{4}$ cycles of loading. It can be also remarked from the Figure 10 that, regarding the left interface failure (Figure 8), the resistor R4 was broken before R3. In fact, by analysing the progression of the failure at the interface crossed by $R 3$ and $R 4$, it can be seen that, 
in the vicinity of the resistor R3, a part of the shear failure is propagated in the asphalt concrete mix before coming back at the interface.

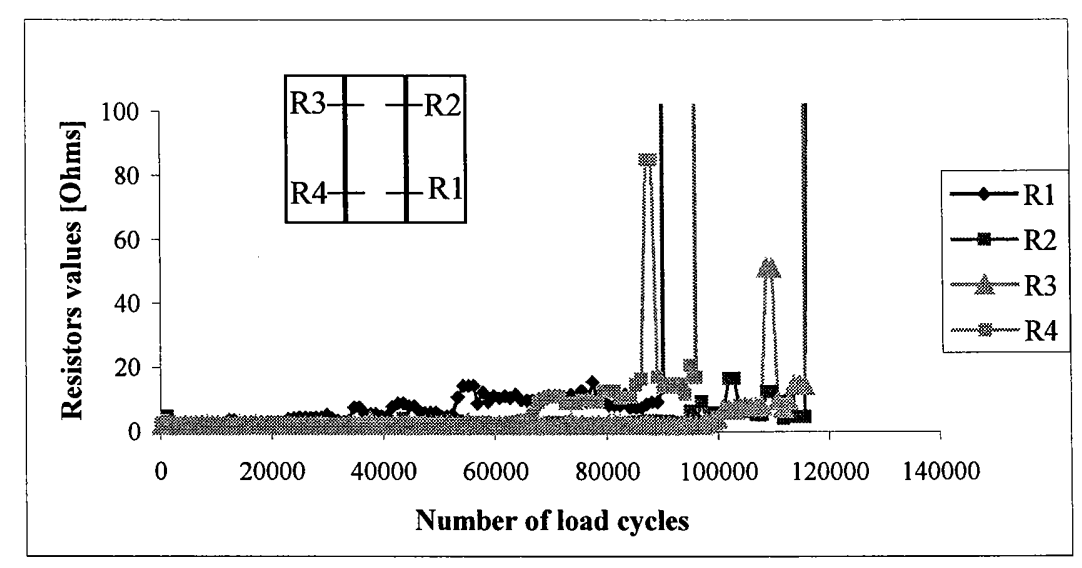

Figure 10. Resistors values versus number of load cycles curve (test $29 G$ )

\subsection{Shear force and displacement}

Figures 11 and 12 present, respectively, typical evolutions, observed during the experimental campaign, of the amplitude (peak to peak of the sinusoidal signal) and the average value of the shear force and the relative displacement (at the interfaces) versus the number of load cycles (test 2_9G).

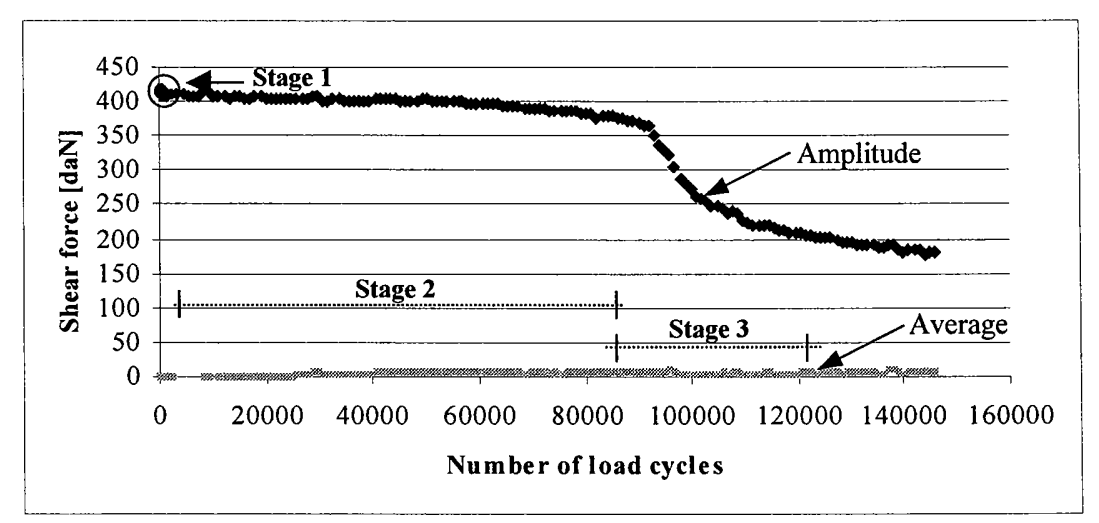

Figure 11. Evolutions of the amplitude (peak to peak) and average of the shear force versus the number of load cycles (test 2_9G) 
The average's evolution of the shear force, presented in Figure 11, clearly shows that the interfaces between asphalt mix layers (Figure 8 ) are symmetrically subjected all through the fatigue test.

Generally encountered in the literature, the evolution of the force (or displacement) against the number of load cycles can be divided into three stages. In a first stage hardly distinguished from Figure 11, first hundred cycles (Ashayer and Soltani, 1998), an internal heating process lead to decrease the shear force amplitude. In a second stage, longer than the first one, the interfaces fail progressively, and the shear force amplitude decreases faintly. In a third stage, the force amplitude decreases distinctly, meaning a fast propagation of the interfaces failures and the phenomena of aggregates interlock become dominating. These observed decreases of the shear force amplitude during the fatigue test also mean the lose of shear stiffness of the emulsion.

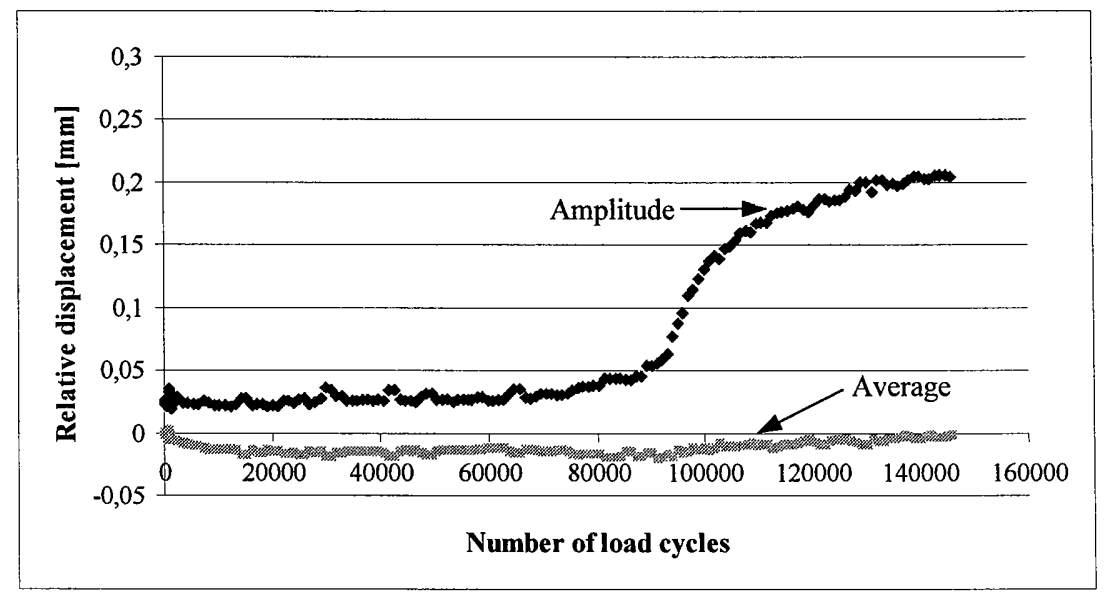

Figure 12. Evolutions of the amplitude (peak to peak) and average of the relative displacement versus the number of load cycles (test 2_9G)

\subsection{Initial load level-number of cycles to failure}

The nominal initial shear stress half-amplitude applied $\Delta \tau$ is computed by dividing the shear force amplitude (peak to peak) $\Delta F$ by the initial cross sectional sheared area $S$ measured at the interfaces:

$$
\Delta \tau=\frac{\Delta F}{2 \cdot S}
$$


Where:

- $\Delta F:$ Force amplitude (peak to peak);

$-S$ : Cross-sectional sheared area (measured at both interfaces).

The number of cycles to failure $\mathrm{N}_{\mathrm{f}}$ can be defined conventionally by getting half the initial force $\left(\mathrm{F}_{0} / 2\right)$ when the imposed displacement is constant or by getting half the initial displacement $\left(u_{0} / 2\right)$ when the imposed force is constant all through the fatigue test. As it can be remarked from Figure 12, the amplitude's evolution of the imposed displacement is not constant during the shear fatigue test. Hence, the number of cycles to failure can't be defined by means of the conventional criterion mentioned above. The number of cycles to failure could also be estimated by getting half of the initial shear stiffness $\left(\mathrm{K}_{0} / 2\right)$.

Another way to define the number of cycles to failure is to use the "resistor failure criterion" $N_{f}(R)$. Since the resistor break and the interface failure are dependent to each other, the number of cycles to failure of the interface is assessed as being the maximum of the number of cycles of resistors.

The initial shear stress half-amplitude and the number of cycles to failure, for each fatigue shear test, are presented in Table 2.

Table 2. Initial shear stress half-amplitude and number of cycles to failure for each test

\begin{tabular}{|c|c|c|c|c|c|}
\hline \multirow{2}{*}{ Test } & \multirow{2}{*}{$\Delta \tau[\mathrm{MPa}]$} & \multicolumn{4}{|c|}{$\mathrm{N}_{\mathrm{f}}(\mathrm{R})$} \\
\cline { 3 - 6 } & & $\mathrm{R} 1$ & $\mathrm{R} 2$ & $\mathrm{R} 3$ & $\mathrm{R} 4$ \\
\hline 2_4G & 0,614 & 24465 & 12073 & $\mathbf{2 9 6 8 2}$ & $\mathbf{2 9 6 8 2}$ \\
\hline 2_8G & 0,496 & $\mathbf{8 6 9 7 0}$ & 82079 & $\mathbf{8 1 1 0 1}$ & Defective \\
\hline 2_9G & 0,489 & 91079 & 113568 & $\mathbf{1 1 6 5 0 3}$ & 95970 \\
\hline 2_5G & 0,466 & 203061 & $\mathbf{2 0 6 5 2 6}$ & 205547 & 195235 \\
\hline 2_5D & 0,462 & 134341 & 173091 & 173091 & $\mathbf{1 7 5 0 4 7}$ \\
\hline 2_4D & 0,396 & 365220 & 360245 & 361203 & $\mathbf{3 8 3 2 2 4}$ \\
\hline
\end{tabular}

According to Table 2, in most of the tests (2_4D for example), the numbers of cycles of the resistors are in the same level in term of magnitude, therefore interfaces failures are simultaneous. Nevertheless, in some cases (test $24 \mathrm{G}$ for instance), there are some differences between numbers of cycles that are due to a propagation of some parts of the shear failure in the asphalt concrete mix and not at the interface. As mentioned earlier, the number of cycles to failure for each test is the maximum of the numbers of cycles given by the resistors. 
The $\mathrm{S} / \mathrm{N}$ diagram, where $\mathrm{S}$ is the applied solicitation and $\mathrm{N}$ the number of load cycles to failure, is plotted in a logarithmic or in a semi-logarithmic diagram (Whöler diagram, where generally is $\mathrm{S}$ on the linear axis and $\mathrm{N}$ on the logarithmic axis). Here, the solicitation, $S$, is shear stress half amplitude.

As shown in Figure 13, shear fatigue results are plotted in terms of initial shear stress half-amplitude $\Delta \tau$ versus decimal logarithm of the number of cycles to failure $N_{f}$.

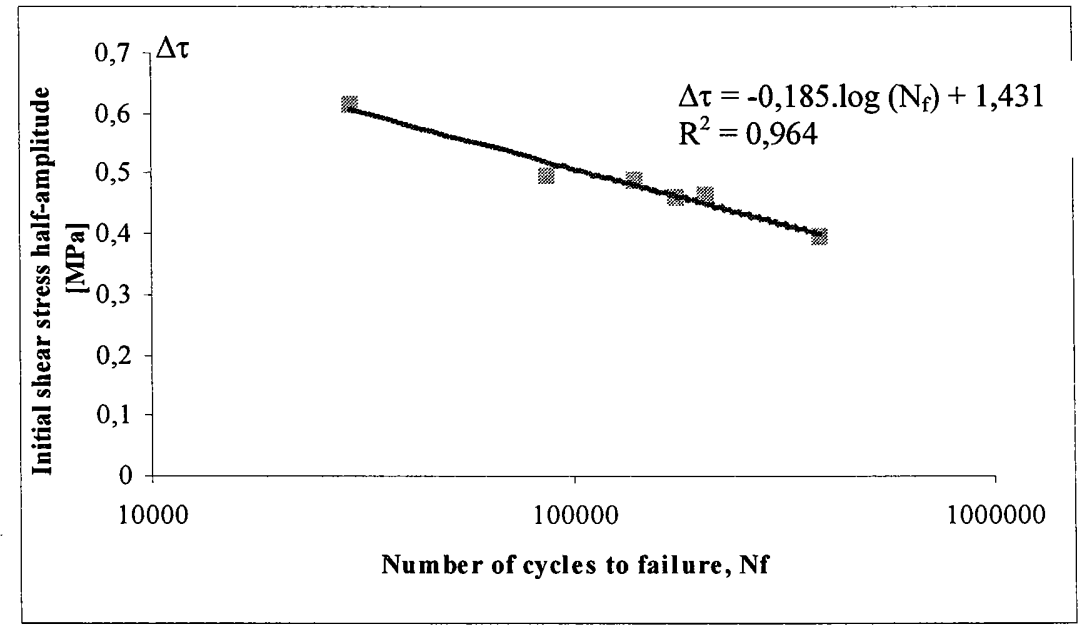

Figure 13. Evolution of the number of cycles to failure versus initial shear stress half-amplitude

According to Figure 13, within the range of $10^{4}$ to $10^{5}$ cycles of loading, a linear evolution of the initial shear stress half-amplitude with the decimal logarithm of the number of cycles to failure is observed.

Under constant amplitude loading, a linear representation of the fatigue results in a semi-logarithmic diagram is [2]:

$$
\Delta S\left(N_{f}\right)=\Delta S_{c r}+C \cdot \log N_{f}
$$

Where:

$$
\begin{aligned}
& \Delta S\left(N_{f}\right): \text { Initial half-amplitude loading; } \\
& N_{f}: \text { Number of load cycles to failure; }
\end{aligned}
$$


$\Delta S_{c r}:$ Static strength;

$C$ : Material parameter (the slope of the initial half-amplitude load versus number of load cycles to failure curve).

It could be noticed that the representation of the fatigue data presented in Equation [2] includes the results from a monotonic test (failure at $N_{f}=1$ ), from which the static strength $\Delta S_{c r}$ derived, by using an "equivalent" frequency or an "equivalent" displacement rate criterion.

French fatigue cracking model (LCPC, 1994) derived from bending fatigue tests (NF P 98-261-1) performed on laboratory asphalt concrete mix specimens, and is presented hereafter in Equation [3].

$$
\varepsilon_{t}=\varepsilon_{6} \cdot\left(\frac{N_{f}}{10^{6}}\right)^{b}
$$

Where $\varepsilon_{t}$ and $\varepsilon_{6}$ are the horizontal tensile strains at the bottom of the asphalt layers for a given number of cycles to failure $N_{f}$ and for $10^{6}$ cycles to failure respectively, $b$ is the slope of the horizontal tensile strain $\varepsilon_{t}$ versus number of load cycles to failure $N_{f}$ curve. This slope $b$, obtained from these laboratory tests, is about -0.2 . Bending fatigue tests, from which the fatigue-cracking model [3] derived, are carried out at low loading levels that lead to high number of load cycles (within the range of $10^{5}$ to $10^{7}$ cycles).

From shear fatigue tests performed on emulsion, the representations of the tack coat fatigue law in a semi-logarithmic diagram and in a logarithmic diagram are as follows:

$$
\text { Semi-logarithmic diagram: } \Delta \tau\left(N_{f}\right)=1,43-0,185 \cdot \log N_{f}
$$

$$
\text { Logarithmic diagram: } \Delta \tau\left(N_{f}\right)=\Delta \tau_{6} \cdot\left(\frac{N_{f}}{{ }_{10}^{6}}\right)^{b}
$$

Where $\Delta \tau_{6}=0.338 \mathrm{MPa}$ and $b=-0.159$.

By comparing Equation [3] with Equation [5], we can see that the slope of the initial shear stress half-amplitude versus number of load cycles to failure curve is $b=-0.159$ and remark that it's of the same order as the one presented above $(b=-0.2)$ obtained with bituminous materials. 


\section{From research to practice}

Roughly speaking, fatigue tests are expensive and take much time before being used for any research conclusion. For instance, during the experimental campaign described in this paper, a shear fatigue test takes at least three days, without taking into account time for fatigue test preparation.

Since there are few studies performed on interface behaviour, the main objective of the research study presented here is to establish a fatigue law of a standard emulsion using current parameters. Hence, when we would like to investigate all test parameters in detail (asphalt mix type, tack coat type, application rate, temperature, frequency, roughness at the interface, etc.), the fatigue tests should be very heavy and will take much time.

A suitable finding for road contractors should be to identify tack coat fatigue properties from simple tests, such as monotonic tests. To come up to this request, a series of monotonic shear tests was performed on the same specimen type tested in shear fatigue by means of the shear test configuration shown in Figure 5. The influence of the loading rate on the interface shear strength was investigated by selecting four displacement rate levels $\dot{u} \approx 0.01 \mathrm{~mm} / \mathrm{s}, \dot{u} \approx 0.15 \mathrm{~mm} / \mathrm{s}$, $\dot{u} \approx 1.5 \mathrm{~mm} / \mathrm{s}$ and $\dot{u} \approx 3 \mathrm{~mm} / \mathrm{s}$. At least three shear tests were performed for each displacement rate. Hence, twenty-one direct shear tests were carried out at $5^{\circ} \mathrm{C}$, and the results of fourteen tests of them are used to plot the interface shear strength against the decimal logarithm of the shear displacement rate (Figure 14) (Diakhate, 2003).

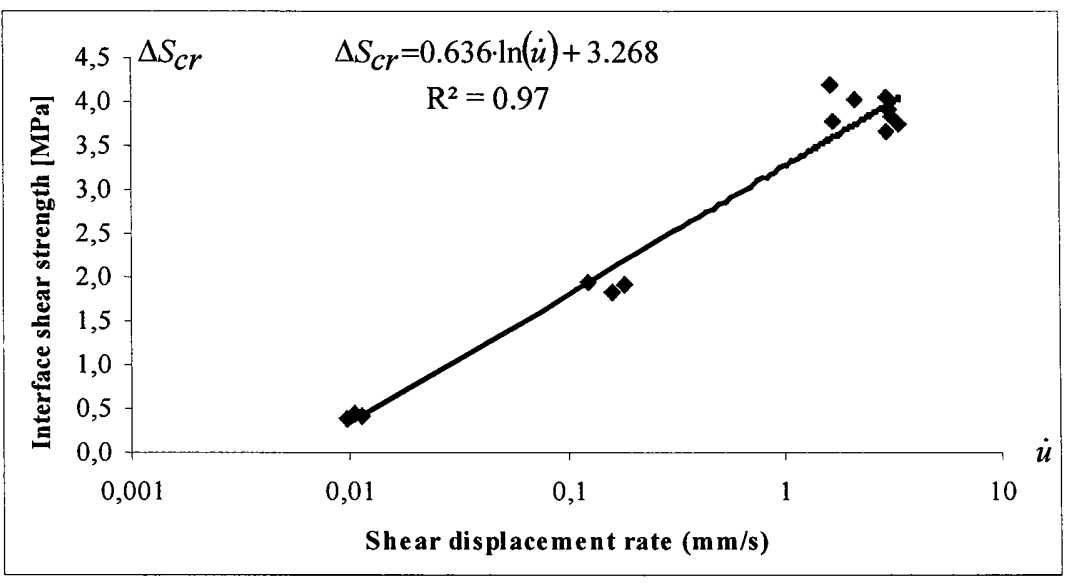

Figure 14. Interface shear strength versus displacement rate evolution 
The main question is how to closely connect the shear fatigue results to those from direct shear tests? Since fatigue shear tests are performed at $5^{\circ} \mathrm{C}$ and at $1 \mathrm{~Hz}$, direct shear tests should be conducted at the same conditions in terms of loading rate. Hence, from Figure 14, the shear strength $\Delta S_{c r}$ that should be obtained from a direct shear test carried out at $5^{\circ} \mathrm{C}$ and at a shear displacement rate (which corresponds to an "equivalent" frequency of $1 \mathrm{~Hz}$ ) is extrapolated. A first attempt has been investigated: for the materials combination tested in this study at the selected test parameters $\left(1 \mathrm{~Hz}, 5^{\circ} \mathrm{C}\right.$, several shear displacement rates), shear fatigue and monotonic shear behaviours may be connected by use of an "equivalent" loading rate criterion. In other words, shear fatigue properties are dependent to the loading rate as well as the shear strengths (monotonic test). This is probably due to the viscoelastic behaviour of the emulsion. However, connecting shear fatigue properties to those from monotonic shear tests needs more investigations on interface shear fatigue behaviour within the range $10^{2}$ to $10^{4}$ number of cycles.

\section{Conclusion}

In this research, shear fatigue tests at constant temperature $\left(5^{\circ} \mathrm{C}\right)$ and constant frequency $(1 \mathrm{~Hz})$ were performed on asphalt concrete mix layers interface with emulsion. A setting up procedure of resistors (thin silver paint) is used to detect interface failures. Resistors values, shear displacement and force at the interface were recorded during the tests. Typical evolutions of the force and the displacement with the number of load repetitions are presented in this paper. The resistor values versus the number of load cycles curve is also presented in this paper.

The research led to the following major findings about emulsion shear fatigue behaviour:

- Under a shear fatigue test, the force evolution at the interface may be described, overall, into two stages: in the first one, interfaces fail progressively, and force amplitude decreases linearly; in the second stage, the force amplitude decreases distinctly, meaning a fast propagation of the failure; this decrease also means the lose of shear stiffness of the tack coat and phenomena of aggregates interlock become dominating.

- The resistors measured values were used to compute the number of cycles to failure of the test, since resistors break and interfaces failures are dependent to each other. The initial shear stress half-amplitude applied and the number of cycles to failure computed for each test were used to derive the shear fatigue behaviour of the tack coat.

- As mentioned earlier, the success of mechanistic design methods for pavement structures depends on a reliable interface condition model. Since the interface shear fatigue behaviour is derived, it seems worth examining to introduce the interfaces shear fatigue criterion in mechanic design methods for pavement structures. Modelling a multi-layered pavement structure in which tack coat film law is taken 
into account can lead to better prevent the sliding and the complete separation of layers. By implementing the tack coat film behaviour into the pavement structure modelling, an optimisation of tack coat, through its formulation and its application rate (thickness), can be done.

- Under direct shear tests, the interface shear strength increases linearly with the decimal logarithm of the displacement rate. This result may be explained by the viscoelastic behaviour of the emulsion. Fatigue tests can be used for a comparative evaluation of the durability for different interfaces. Unfortunately, fatigue tests need much time when we would like to investigate more interface test parameters. Hence, a suitable finding for road contractors should be to develop a model, which can closely connect shear fatigue properties to those from direct shear test; thus, fatigue properties could be evaluated from simple monotonic tests. A first attempt had been done and is going to be more analysed.

Further researches are recommended to improve modelling of the asphalt concrete mix layer interface:

- Direct shear tests with or without normal load as well as shear fatigue tests should be conducted at several temperatures to better understand how temperature influences the interface model parameters;

- More interface testing should be conducted at several shear displacement rates for the direct shear tests, and at several frequencies of loading for the shear fatigue tests to determine their influences on the interface model parameters;

- Additional research should be done to investigate the effects of the size of asperities at the interface as well as of the type and quantity of tack coat on interface behaviour;

- Additional shear fatigue tests should be conducted to derive the interface behaviour within the range of $10^{2}$ to $10^{4}$ cycles.

\section{Acknowledgements}

The Centre de recherche et développement Eurovia supported the research described herein. The authors would like to express their appreciations to the sponsor, through $\mathrm{H}$. Goacolou and M. Maze (Eurovia), and to all those who provided valuable help in conducting this project.

\section{Bibliography}

Ashayer Soltani M.A., Comportement en fatigue des enrobés bitumineux, Thèse de Doctorat, INSA de Lyon, 1998. (In French)

Collop A. C., Thom N. H. And Sangiorgi C., Assessment of bond condition using the Leutner shear test, ICE J. Transp., Vol. 156, No. TR4, 2003, p. 211-217. 
Diakhate M., Comportement en fatigue des couches d'accrochage dans une structure de chaussée, Mémoire de DEA, Laboratoire 3MsGC, université de Limoges, 2003. (In French)

Laveissiere D., Modélisation de la remontée de fissure en fatigue dans les structures routières par endommagement et macro-fissuration, de l'expérimentation à l'outil de dimensionnement pour l'estimation de la durée de vie, Thèse de Doctorat, Laboratoire 3MsGC, Université de Limoges, 2002. (In French)

LCPC, Setra, Conception et dimensionnement des structures de chaussées, guide technique, France, décembre 1994. (In French)

LCPC, Setra, Réseau routier national, catalogue des structures types de chaussées neuves, France, Edition 1998. (In French)

Millien A., Petit C. and Rosier J., Comportement au cisaillement des couches d'accrochage dans les chaussées, rapport interne, Laboratoire 3MsGC, Université de Limoges, France, 1996. (In French)

Mohammad L.N., Raquib M.A. and Huang B., "Influence of asphalt tack coat materials on interface shear strength", Transportation Research Record, No. 1798, p. 56-65, 2002.

Petit C., Laveissiere D. and Millien A., "Modelling of reflective cracking in pavements: fatigue under shear stresses", Proceedings of the $3^{\text {rd }}$ International Symposium on $3 D$ Finite Element for Pavement Analysis, Design and Research, Amsterdam, The Netherlands, 2-5 April 2002, p. 111-123.

Romanoschi A.S., Characterization of pavement layer interfaces, Ph.D Louisiana State University, Baton Rouge, August 1999.

Romanoschi A.S. and Metcalf J.B., "Characterization of asphalt concrete layer interfaces", Transportation Research Record, No. 1778, 2001, p. 132-139.

Uzan J., Livney M. and Eshed Y., "Investigation of adhesion properties between asphaltic concrete layers", Proceedings of Asphalt paving technology, Vol. 47, 1978, p. 495-521.

Received: 1 December 2003

Accepted: 2 February 2005 